\title{
Deuda privada y derechos humanos
}

\author{
Private debt and buman rights
}

Divida privada e direitos bumanos

Dette privée et droits de l'bomme

私人债务与人权

\section{Juan Pablo Bohoslavsky ${ }^{1}$ \\ Universidad Nacional de Río Negro - Argentina}

Revista Derechos en Acción ISSN 2525-1678/ e-ISSN 2525-1686

Año 5/N 15 , Otoño 2020 (21 marzo a 20 junio), 27-68

DOl: https://doi.org/10.24215/25251678e388

Recibido: 01/04/2020

Aprobado: 01/06/2020

Resumen: El objetivo de este artículo es contribuir a la comprensión de las violaciones de los derechos humanos que se producen en el ámbito de la deuda privada, centrándose específicamente en la deuda que ofrecen a los particulares y los hogares toda una gama de agentes crediticios que operan tanto en el sector formal como en el informal. Existen dos factores

\footnotetext{
1 Experto Independiente en Deuda y Derechos Humanos de la ONU (2014-2020). (ORCID 0000-0002-7059-281X). Actualmente coordina el curso de posgrado en "Derechos humanos y políticas públicas en tiempos de Covid-19" en la Universidad Nacional de Río Negro.

Este artículo se basa en el informe temático que presenté al Consejo de Derechos Humanos de la ONU el 2 de marzo de 2020. El informe se ha basado en las contribuciones recibidas (que se encuentran disponibles en línea www.ohchr.org/EN/Issues/Development/IEDebt/ Pages/ReportPrivateDebt.aspx) como respuesta a la convocatoria pública efectuada durante 2019. También se benefició de las consultas y los numerosos debates que se mantuvieron con diversxs especialistas en Princeton, Nairobi, Buenos Aires y Ginebra, entre octubre y diciembre de 2019. Quisiera agradecer a todxs Ixs especialistas y partes interesadas que contribuyeron durante el proceso, en particular a la Friedrich Ebert Stiftung y a la Open Society Foundation, así como al personal de la Oficina del Alto Comisionado de las Naciones Unidas para los Derechos Humanos (ACNUDH), que ofrecieron aportes valiosos. Finalmente, quisiera agradecer a Lena Lavinas por sus comentarios a los borradores de este artículo.
} 
que impulsan el incremento del endeudamiento privado: en primer lugar, la pujanza de la oferta crediticia del sector financiero, cuyos promotores son la liberalización del mercado y el aumento de la financierización, y en segundo lugar, la reconfiguración de muchas de las necesidades humanas de reproducción social que se convierten en necesidades financieras insatisfechas, unida al estrepitoso fracaso del Estado en cuanto a garantizar los derechos económicos, sociales y culturales de todxs. El artículo concluye que las deudas privadas no solo pueden constituir la causa de violaciones de derechos humanos sino también su consecuencia. Estudia específicamente las repercusiones negativas que tienen, para los derechos humanos, las deudas relacionadas con el microcrédito, la salud, la educación y la vivienda, las prácticas coactivas y abusivas de cobro, la criminalización de los deudores, las deudas de Ixs consumidorxs y las deudas migratorias, así como la servidumbre por deudas.

Palabras clave: deuda privada, mercado, derechos sociales, derechos humanos.

\begin{abstract}
The objective of this article is to contribute to the understanding of human rights violations that occur in the field of private debt, specifically in the debt offered to individuals and households by credit agents operating in both the formal and informal sector. There are two factors that promote private indebtedness: first, the credit supply of the financial sector, whose promoters are the liberalization of the market and the increase in financing. And secondly, the reconfiguration of many of the human needs of social reproduction that become unmet financial needs, along with the failure of the State to guarantee the economic, social and cultural rights. The article concludes that private debts can not only constitute the cause of human rights violations, but also their consequence. It specifically studies the negative repercussions, for human rights, of debts related to microcredit, health, education and housing, coercive and abusive collection practices, criminalization of debtors, consumer debts and immigration debts, as well as debt bondage.
\end{abstract}

Keywords: private debt, market, social rights, human rights.

Resumo: 0 objetivo deste artigo é contribuir a compreensão das violações de direitos humanos que ocorrem no campo da dívida privada, concentrando-se especificamente na dívida oferecida a indivíduos e famílias por toda uma gama de agentes de crédito que operam nos setores formal 
como no informal. Existem dois fatores que impulsionam o aumento do endividamento privado: primeiro, a força da oferta de crédito do setor financeiro, cujos promotores são a liberalização do mercado e 0 aumento da financeirização, e em segundo lugar, a reconfiguração de muitas das necessidades humanas de reprodução social que se tornam em necessidades financeiras insatisfeitas, juntamente com 0 fracasso escandaloso do Estado em garantir os direitos econômicos, sociais e culturais de todos. 0 artigo conclui que as dívidas privadas não somente podem constituir a causa das violações dos direitos humanos mas também suas conseqüências. Estuda especificamente as repercussões negativas que têm, para os direitos humanos, as dívidas relacionadas ao microcrédito, a saúde, a educação e a moradia, as práticas de cobrança coercitiva e abusiva, a criminalização dos devedores, as dívidas de consumidores e as dívidas de imigração, assim como a servidão por dívida.

Palavras-chave: dívida privada, mercado, direitos sociais, direitos humanos Résumé: L'objectif de cet article est de contribuer à la compréhension de celles violations des droits de l'homme qui se produisent dans le champ de la dette privée, en se concentrant spécifiquement sur la dette offerte aux particuliers et aux ménages par des gents de crédit qui opèrent dans les secteurs formelles et informeles. II y a deux facteurs à l'origine de l'augmentation de l'endettement privé: premièrement, l'offre de crédit du secteur financier, où la libéralisation des marchés et l'augmentation du financement sont encourageés, et deuxièmement, la reconfiguration de nombreux besoins humains qui deviennent des besoins financiers non satisfaits, et en plus l'incapacité de l'État à garantir les droits économiques, sociaux et culturels. L'article conclut que les dettes privées peuvent non seulement constituer la cause de violations des droits de l'homme mais aussi leur conséquence. On étudie spécifiquement les répercussions négatives, pour les droits de l'homme, des dettes liées au microcrédit, à la santé, à l'éducation et au logement, aux pratiques de recouvrement coercitives et abusives, à la criminalisation des débiteurs, aux dettes des consommateurs et les dettes d'immigration, ainsi que la servitude pour dettes.

Mot-clés: Mots clés: dette privée, marché, droits sociaux, droits de I'homme.

摘要: 本文的目的是促进对私人债务领域中发生的侵犯人权行为的 理解, 特别是侧重于经营这两种行为的各种信贷机构向个人和家庭 
提供的债务. 在正式和非正式部门. 导致私人债务增加的因素有两 个:第一, 金融部门信贷供应的实力, 其推动力是市场自由化和金融 化程度的提高; 第二, 许多金融机构的重新配置. 人类对社会再生 产的需求已成为无法满足的财政需求, 再加上国家在保障所有人的 经济, 社会和文化权利方面的巨大失败. 文章得出结论, 私人债务不 仅可以构成侵犯人权的原因, 而且可以构成其后果. 它专门研究了 对人权的负面影响, 这些负面影响涉及与小额信贷, 健康, 教育和住 房, 强制性和滥用收款行为, 将债务人定罪, 消费者的债务和移民债 务以及债务束缚.

关键词: 债务, 市场, 社会权利, 人权

\section{Introducción}

La deuda de las personas o de los hogares no es un problema per se. La capacidad de obtener préstamos dentro de los límites de la propia solvencia financiera puede mejorar el nivel de vida de las personas y darles acceso a unos servicios que, de otro modo, quedarían fuera de su alcance. También puede ayudar a activar y apuntalar la economía. En ocasiones, la deuda de los particulares o de los hogares también puede favorecer la movilidad o la integración sociales y ser un factor determinante de la inclusión social.

Sin embargo, el endeudamiento excesivo (entendido, a los efectos de este artículo, como una deuda cuya amortización y gastos conexos priven al deudor de los recursos que necesita para ejercer sus derechos humanos de manera sostenible), las cláusulas contractuales abusivas y las prácticas de cobro abusivas se convierten en una carga y en una amenaza para los particulares o los hogares, ya que pueden convertirse, para muchxs de ellxs, en una trampa que ponga en peligro el ejercicio de sus derechos humanos. A su vez, la deuda privada no solo puede ser la consecuencia de violaciones de derechos humanos sino también su causa: la pobreza y la desigualdad en un contexto de creciente financierización de bienes públicos empuja a la gente a que contraiga más y más deuda privada. 
El notable incremento de la deuda privada se debe, en gran medida, a la deuda empresarial y, en menor medida, a la deuda de los hogares, los préstamos y los títulos de deuda ${ }^{2}$, lo que tiene profundas repercusiones sobre los sistemas económicos y financieros mundiales y sobre la capacidad de los Estados de cumplir sus obligaciones de derechos humanos. Según la Conferencia de las Naciones Unidas sobre Comercio y Desarrollo (UNCTAD), a finales de 2017, el volumen de la deuda mundial ascendía a 213 billones de dólares de los Estados Unidos, suma que equivalía al $262 \%$ del producto interno bruto (PIB) mundial y que representaba un incremento considerable en comparación con las de 2008 (240 \%) y 1980 (140 \%). La acumulación de un volumen de deuda privada que representaba más de dos tercios de la deuda mundial en 2017 contribuyó, en gran medida, al fuerte aumento general de la deuda ${ }^{3}$, cuyo común denominador fue el endeudamiento privado en moneda extranjera. Tales tendencias revelan que ha habido un cambio fundamental en las obligaciones que tienen los Estados de garantizar el acceso, la disponibilidad, la asequibilidad y la calidad del ejercicio de los derechos humanos, en favor del poder de los mercados liberalizados ${ }^{4}$.

Según lo declaró el Consejo de Derechos Humanos de la ONU en $2019^{5}$, la cuestión de la deuda externa, tanto pública como privada, está íntimamente ligada al aumento de la desigualdad en el mundo y a los obstáculos derivados de la carga de la deuda que se oponen al desarrollo humano sostenible, que comprende el cumplimiento de lo dispuesto en la Agenda 2030 para el Desarrollo Sostenible gracias a una financiación adecuada.

\footnotetext{
2 Véase Conferencia de las Naciones Unidas sobre Comercio y Desarrollo, Trade and Develoment Report 2019, pp. 74 y 75.

3 Ibid., p. 76.

4 Maurizio Lazzarato, Governing by debt, Semiotext(e), 2015; Susanne Soederberg, Debtfare State and the Poverty Industry: Money, Discipline and Surplus Population (Routledge, 2014).

5 Resolución 40/08.
} 
El rol del Estado es vital para contrarrestar la asimetría de poder contractual entre las partes de un contrato de deuda privada a fin de lograr una protección efectiva de los derechos humanos ${ }^{6}$. Tal como lo sostiene David Kinley, existen dos problemas principales cuando lidiamos con nociones básicas de responsabilidad de las instituciones financieras. Uno es el narcisismo -las externalidades en materia de derechos humanos son incuantificables y/o irrelevantes-, el otro es el excepcionalismo -la percepción de que, dado su poder, el sector financiero justifica su existencia como un fin en sí mismo. ${ }^{7}$

Desafortunadamente, pensar la deuda privada desde una perspectiva de derechos humanos, de una manera sistemática, no constituye una práctica común en ámbitos académicos y de políticas públicas si se la compara, por ejemplo, con la atención que merecen los problemas vinculados a la deuda pública. Así, el propósito de este artículo es contribuir a la discusión en torno a las violaciones de derechos humanos en el contexto de la deuda privada, focalizando en la deuda de los individuos y del hogar.

Dentro de la categoría de "deuda de los particulares y de los hogares" se pueden incluir muchas formas de deuda privada, así como diversos tipos de acreedores y deudores. Incluso se puede incluir en ella a las pequeñas empresas familiares que obtienen crédito por cauces formales e informales. Las vulneraciones de derechos humanos más directas y atroces que sufren los prestatarios privados afectan a particulares y hogares endeudados, sobre todo en el caso de las personas y los hogares que viven en la pobreza o la marginación o en el de aquellos a los que se empuja a caer en la "trampa de la deuda". La deuda empresarial solo se estudiará en un plano general para ofrecer una perspectiva del peso que tiene en la economía mundial. No obstante, la deuda privada empresarial, unida a la deuda de los

\footnotetext{
6 James Galbraith, "Inequality, debt, and human rights", Humanity, 2019, Vol. 10:3, pp. 460-4. 7 David Kinley, Necessary Evil. How to Fix Finance by Saving Human Rights, Oxford University Press, New York, 2018, p. 4.
} 
hogares, también puede repercutir gravemente en la economía, y por tanto en los derechos humanos, como se explica en la Sección II.

Este artículo se organiza del siguiente modo. La Sección II explica los vínculos que existen entre la creciente deuda privada, la macroeconomía, la desigualdad y la deuda pública. La Sección III presenta las tipologías de endeudamiento privado incluyendo las deudas relacionadas con el microcrédito, la salud, la educación y la vivienda, las prácticas coativas y abusivas de cobro, la criminalización de los deudores, las deudas de los consumidores y las deudas migratorias, así como la servidumbre por deudas. La Sección IV describe los estándares de derechos humanos más relevantes en materia de deuda privada. La Sección V presenta las conclusiones.

\section{Deuda privada, macroeconomía y deuda pública}

Los servicios de producción de crédito y de intermediación financiera fuertemente privatizados han sido el principal factor que ha impulsado el fuerte incremento de la deuda privada en las economías en desarrollo desde el decenio de $1980^{\circ}$. Después de la crisis financiera de 2008, se han seguido expandiendo el sistema bancario paralelo y otras actividades crediticias, a pesar de los esfuerzos regulatorios realizados. Según la UNCTAD, desde entonces el volumen de los servicios de intermediación financiera extrabancaria se ha duplicado en comparación con el de los servicios de las bancas convencional y pública, y ha registrado un porcentaje del 48,2 \% del total de los activos financieros mundiales, que supera el porcentaje (43,9\%) de los bancos comerciales y de las instituciones financieras públicas.

A pesar de que el endeudamiento público de los países en desarrollo ascendió al 51 \% en 2017, es evidente que el fenómeno más alarmante es el auge sin precedentes de la deuda privada. Si bien cabe achacar una gran proporción de esta deuda privada

8 UNCTAD, Trade and Development Report 2019, p. 76. 
a que los países en desarrollo de ingresos altos han podido dotarse de unos sistemas financieros y bancarios nacionales más complejos y han tenido mayores facilidades para acceder a los mercados financieros internacionales, también se han observado unas tendencias de incremento del endeudamiento general de los países en desarrollo de ingresos medianos y bajos desde 2012 . Por ejemplo, la relación entre la deuda pública y el PIB de los países de ingresos altos pasó del $34 \%$ en 2008 al $50 \%$ en 2017 y su endeudamiento total alcanzó el $215 \%$ del PIB, debido, en gran medida, al pronunciado incremento de la deuda privada en la etapa inmediatamente posterior a la crisis financiera mundial $^{9}$. A pesar de la tendencia alcista de la deuda de los hogares que registraron las economías emergentes, que se incrementó del $25,4 \%$ en 2011 al $40 \%$ en 2018, también la concesión de préstamos a empresas no financieras influyó decisivamente en el aumento general de la deuda privada no financiera.

En varios estudios se ha señalado que hay una relación estrecha entre la acumulación de deuda privada, la inestabilidad macroeconómica y las crisis de deuda soberana: el auge de la deuda privada ha ido ligado, en algunos países, a la desaceleración económica y suele constituir un indicador preciso de inestabilidad financiera ${ }^{10}$. Asimismo, el aumento de la desigualdad puede conducir a un exceso de préstamos y empréstitos privados, lo que, a su vez, puede repercutir en la estabilidad financiera y provocar, a largo plazo, una crisis de la deuda ${ }^{11}$.

La deuda de los particulares y de los hogares representa una proporción significativa de la deuda privada de la mayoría de los países y puede resultar de la adopción de una serie de medidas económicas, como medidas de privatización, de austeridad o de flexibilización del mercado laboral, que rebajan el salario

9 Ibid., p. 77.

10 Juan Pablo Bohoslavsky, "Economic inequality, debt crises and human rights", Yale Journal of International Law, vol. 41, núm. 2 (2016).

11 A/HRC/31/60, párr. 22. 
de los trabajadores no calificados y alimentan la desigualdad ${ }^{12}$. Por ejemplo, aunque el desempleo haya registrado su cifra más baja en casi cuatro decenios en los países pertenecientes a la Organización de Cooperación y Desarrollo Económicos, los salarios reales no se han recuperado, o han crecido a un ritmo más lento que el del decenio anterior a la crisis financiera de $2008^{13}$. Por otra parte, han subido los gastos de salud, vivienda, alimentación y educación, pero se han recortado o reducido las prestaciones sociales.

A medida que ha aumentado la diferencia entre los ingresos nominales y las necesidades de efectivo, los hogares han recurrido cada vez más al endeudamiento para satisfacer sus necesidades de consumo. Problemas parecidos han afrontado los países en desarrollo, en los que la expansión del crédito al consumo ha contribuido considerablemente al crecimiento del PIB pero muchos consumidores han entrado en un ciclo de endeudamiento excesivo y pobreza, debido a esos préstamos. Incluso el Fondo Monetario Internacional (FMI) ha reconocido que el crecimiento de la deuda de los hogares puede frenar la recuperación económica, que ya es débil, y prolongar la actual fase de crecimiento escaso ${ }^{14}$.

Asimismo, una deuda de los hogares elevada puede repercutir negativamente en la economía. Llegado a cierto punto, el endeudamiento lastra la productividad, el consumo y el crecimiento y provoca un desequilibrio insostenible ${ }^{15}$. Si la deuda privada es demasiado alta, los consumidores y las empresas tienen que desviar una proporción mayor de sus ingresos para pagar los intereses y el principal de esa deuda, con el resultado

\footnotetext{
12 Jean-Michel Servet y Hadrien Saiag, "Household over-indebtedness in Northern and Southern countries: A macro-perspective", Microfinance, Debt and Over-Indebtedness, IsabeIle Guérin y otros (eds.) (Routledge, 2014), p. 26.

13 Organización de Cooperación y Desarrollo Económicos, Economic Outlook, vol. 2019, n 1, p. 8.

14 FMI, Informe sobre la estabilidad financiera mundial 2019, Ginebra, 2017, p. 53.

15 Ibid., p. 78. Véase también Servet y Saiag, "Household over-indebtedness in Northern and Southern countries", p. 28.
} 
de que gastan e invierten menos. En un número de crisis financieras, el aumento de la deuda de los consumidores ha creado burbujas de activos de inversión, que han dado lugar a colapsos financieros. En muchos casos, la deuda privada se nacionaliza mediante programas de rescate financiero, que agudizan los desequilibrios del sector público y pueden provocar crisis de la deuda soberana ${ }^{16}$. El auge sin precedentes de la deuda privada constituye, sin duda, el mayor pasivo contingente de la deuda pública en caso de crisis de deuda ${ }^{17}$.

Está generalmente reconocido que hay una correlación entre la deuda privada y la desigualdad. En diversos estudios se indica que la deuda de los hogares y la porción de ingresos más elevados están correlacionados positivamente; por tanto, la desigualdad de ingresos aumenta cuando crece la deuda privada $^{18}$. Según la argumentación basada en la demanda de crédito, la deuda privada se acrecienta cuando los hogares tratan de mantener ciertos niveles absolutos o relativos de consumo en una situación de desigualdad creciente; en otros términos, las personas toman más empréstitos para mantener su nivel de vida. Este fenómeno también puede agravarse a causa de la desigualdad; en una sociedad muy desigual, a los hogares de ingresos bajos les puede ir peor que a los que tienen ingresos idénticos en una sociedad más igualitaria ${ }^{19}$. Además, la solicitud de empréstitos por parte de los hogares se ha convertido en un mecanismo de reproducción social. No cabe duda de que el crédito es cada vez más importante para acceder a los servicios públicos esenciales, como los de educación y salud. Por tanto, el acceso desigual al crédito puede agravar las desigualdades sociales y económicas existentes ${ }^{20}$.

\footnotetext{
16 UNCTAD, Trade and Development Report 2017, Ginebra, 2017, pp. 100 y 106.

17 UNCTAD, Trade and Development Report 2019, pp. 76.

18 Véase también UNCTAD, Trade and Development Report 2017, pp. 103 y 104.

19 Véase $\mathrm{A} / \mathrm{HRC} / 31 / 60$.

20 Lena Rethel, "Financialisation and the Malaysian Political Economy", Globalizations, vol. 7, núm. 4 (2010).
} 
Una política común de respuesta en caso de crisis financiera ha sido la de proteger a las instituciones financieras y las grandes empresas, lo que, de por sí, protege a los hogares más ricos, que son los propietarios de sus activos, en lugar de a los hogares de ingresos medianos y bajos ${ }^{21}$. Además, la mayoría de los países recurren a la austeridad para hacer frente a las crisis financieras, y los recortes drásticos de la protección social y de los empleos del sector público agravan la brecha de la desigualdad. Las medidas de austeridad suelen afectar a quienes se encuentran en situación vulnerable, como los pobres, no a los acreedores. En el caso de las mujeres, el acceso (o la falta de acceso) a la seguridad social y a la deuda privada están ligados estrechamente ${ }^{22}$. Por un lado, el acceso de las mujeres al crédito se puede ver comprometido por los recortes de las prestaciones sociales, que, por otro lado, son esenciales para prevenir el endeudamiento excesivo ${ }^{23}$.

A su vez, el incremento de los niveles de desigualdad puede contribuir, de manera directa o indirecta, a que aumenten la deuda privada y las crisis financieras. En la medida en que la desigualdad de los ingresos guarda una relación directa con la base imponible del impuesto sobre la renta, unos niveles altos de desigualdad indican que la base imponible no es lo suficientemente progresiva. También hay algunos partidarios de la idea de que el incremento de la desigualdad es perjudicial para el crecimiento económico ${ }^{24}$, y los datos empíricos indican que está ligado con el estallido de crisis financieras más frecuentes

\footnotetext{
21 UNCTAD, Trade and Development Report 2017, pp. 108.

22 Luci Cavallero y Verónica Gago, Una lectura feminista de la deuda, Fundación Rosa de Luxemburgo, Buenos Aires, 2019.

23 Julia Callegari, Pernilla Liedgren y Christian Kullberg, "Gendered debt: a scoping study review of research on debt acquisition and management in single and couple households", European Journal of Social Work, 2019, pp. 9.

24 Jonathan D. Ostry, Andrew Berg y Charalambos G. Tsangarides, "Redistribution, Inequality, and Growth", FMI, 2014, pp. 15. Posteriormente el Banco Mundial puso en tela de juicio la verdad de las conclusiones en Poverty and Shared Prosperity 2016: Taking on Inequality (Banco Mundial, Washington, 2016), pp. 71.
} 
y generalizadas ${ }^{25}$. La fiscalidad regresiva y la ralentización del crecimiento económico pueden reducir los ingresos públicos y provocar una dependencia mayor respecto de los préstamos externos, que puede degenerar finalmente en una crisis de la deuda soberana. Los estudios empíricos demuestran que hay, en efecto, una correlación positiva entre la desigualdad de los ingresos, el déficit presupuestario y la deuda soberana ${ }^{26}$.

Por otra parte, el incremento de los ingresos de los más ricos también incrementará sus ahorros, lo que dará lugar a una acumulación inmensa de patrimonio privado. Esta oferta creciente de capital requiere más oportunidades de inversión y, por consiguiente, fomenta la oferta de crédito, incluso la dirigida a los prestatarios que entrañan mayor riesgo ${ }^{27}$.

Cabe recordar que no siempre se dispone de datos mundiales, regionales o a veces nacionales sobre la deuda privada de los hogares que sean exactos y completos. La base de datos sobre la deuda mundial del $\mathrm{FMI}^{28}$ es un instrumento importante en este ámbito, ya que ofrece una combinación de recursos e información; no obstante, también muestra que aún no se dispone de datos sobre la deuda privada de los hogares de muchos países o de períodos largos y comparables. Hay muchos casos de empréstitos y préstamos informales (e incluso ilegales) de particulares y hogares que no están registrados, contabilizados o debidamente calculados. En algunos países, el peso de la economía informal es inmenso, y es probable que una gran parte de la deuda privada de los hogares se mantenga fuera de los sistemas financiero, bancario y extrabancario. Es posible que otra parte de la deuda de los hogares esté mezclada con los cálculos más generales de las corrientes financieras ilícitas, por ejemplo

\footnotetext{
25 UNCTAD, Trade and Development Report 2017, pp. 110.

26 Véase $A / H R C / 31 / 60$.

27 Photis Lysandrou, "Global Inequality, Wealth Concentration and the Subprime Crisis: a Marxian Commodity Theory Analysis", Development and Change, vol. 42, núm. 1 (2011), pp. 183.

28 www.imf.org/external/datamapper/datasets/GDD.
} 
los del total de la deuda que se tiene con los traficantes de migrantes y las deudas de tránsito que se tienen con las autoridades de fronteras corruptas. Por tanto, sería incorrecto adoptar un enfoque puramente cuantitativo de la deuda privada y los derechos humanos en ámbitos como estos. De todos modos, tal planteamiento sigue siendo, en gran medida, imposible sin una recopilación y un análisis adecuados de los datos y que solo ofrecería una mirada parcial de las complejidades de la deuda de los particulares y de los hogares desde una perspectiva de derechos humanos.

\section{Tipología del endeudamiento privado de los hogares: causa y consecuencia de las violaciones a los derechos humanos}

La deuda de los hogares puede ser tanto causa como consecuencia de vulneraciones de los derechos humanos. Frecuentemente, los prestamistas privados se benefician de ello (y lo promueven), incluso en detrimento de los derechos humanos de los prestatarios.

Algunos grupos en situación vulnerable se ven más afectados por los préstamos privados abusivos. Por otra parte, las personas que sufren desigualdades acumulativas o interseccionales suelen ser objeto de múltiples formas de discriminación que, en el ámbito de la deuda privada y los derechos humanos, se traducen en diversas clases de deudas cuyos perjuicios en materia de derechos humanos se agravan recíprocamente.

\section{A. Microcrédito y deuda}

El microcrédito, que está generalizado en muchos países, tenía originalmente como objetivo sacar a las personas de la pobreza mediante su inclusión financiera y su "emancipación económica", sobre todo en las economías emergentes y en desarrollo. Uno de los grupos de destinatarios principales es la población de las zonas rurales, dentro del cual se suele 
otorgar preferencia a las mujeres que toman empréstitos ${ }^{29}$. No obstante, el microcrédito ha resultado tener, en muchos casos, efectos opuestos a los previstos ${ }^{30}$, entre ellos el de incrementar el endeudamiento excesivo y el de crear una "trampa de la pobreza" ${ }^{31}$. En una serie de estudios se ha señalado que los préstamos, en lugar de servir para potenciar el emprendedurismo o las empresas productivas, se han utilizado a menudo para cubrir otros gastos, como el pago de alquileres o fianzas, tasas escolares o gastos de salud. Se ha comprobado que la microfinanciación tiene algunos beneficios a corto plazo, pero también que acrecienta la deuda y, así, agudiza el empobrecimiento, la desintegración familiar e incluso las tasas de suicidio. Además, se han hallado pruebas de que la microfinanciación presenta deficiencias que impiden el desarrollo ${ }^{32}$, con lo cual bloquean otras políticas que podrían tener unos efectos más sostenibles, y entraña mayores costos de oportunidad.

Es cierto que, cuando la microfinanciación está bien dirigida, ha habido casos en que ha beneficiado a los receptores ${ }^{33}$. No obstante, ha habido muchos casos de préstamos y empréstitos excesivos que han ocasionado crisis de microfinanciación en países como Bangladesh, Bolivia, Bosnia y Herzegovina y Camboya. En general, los problemas esenciales son que quienes viven en la pobreza carecen de redes de seguridad cuando aumenta su deuda privada y que algunos Estados no han regulado el microcrédito ni a los prestamistas.

Es una práctica común utilizar los préstamos para sufragar las necesidades básicas y una serie de derechos económicos,

\footnotetext{
29 Comunicación del Comité de Abolición de la Deuda del Tercer Mundo.

30 Véase Isabelle Guérin, Marc Labie y Jean-Michel Servet, The crisis of microcredit (Zed Books, Londres, 2015).

31 Milford Bateman y Ha-Joon Chang, "Microfinance and the Illusion of Development: From Hubris To Nemesis in Thirty Years", World Economic Review, núm. 1 (2012), p. 14.

32 Milford Bateman, Stephanie Blankenburg y Richard Kozul-Wright, The Rise and Fall of Global Microcredit: Development, Debt and Disillusion (Routledge, Nueva York, 2019).

33 Gershman y Morduch, "Credit is not a right", p. 22.
} 
sociales y culturales. Diversos estudios apuntan a que en Camboya, como también al parecer en muchos otros países ${ }^{34}$, la mayor parte de los micropréstamos se utilizaron con fines no productivos, por ejemplo el consumo, el servicio de deudas preexistentes y el pago de gastos imprevistos, como los de enfermedades y accidentes ${ }^{35}$.

Los tipos de interés que se cobran por los préstamos suelen dejar desamparados a los prestatarios cuando aumenta su deuda. En Marruecos, donde se ha promovido el modelo del microcrédito con fondos públicos, esta clase de crédito oscila entre 52 dólares y 5.200 dólares y tiene un elevado tipo de interés medio, del $35 \%{ }^{36}$. Los prestamistas suelen imponer unas cláusulas contractuales leoninas y ejercer prácticas abusivas, como cobrar un tipo de interés del $220 \%$, y los cobradores de deudas también suelen ejercer esa clase de prácticas, entre ellas el acoso, lo que lleva a los prestatarios a la desesperación e incluso al suicidio ${ }^{37}$. Las mujeres suelen ser beneficiarias de microcréditos, por lo que se ven afectadas específicamente por esas prácticas. El hundimiento del sector microfinanciero de Andhra Padresh (India) en 2010 fue un trágico ejemplo de cómo unas instituciones microfinancieras impulsadas por las empresas se volcaron en las personas en situación de pobreza, a quienes cobraron unos tipos de interés exorbitantes por sus préstamos, fomentando así el endeudamiento excesivo y llevando a los prestatarios a una situación extrema, lo cual hizo que se perdieran más de 1.000 millones de dólares en préstamos $^{38}$.

\footnotetext{
34 Hugh Sinclair, Confessions of a Microfinance Heretic: How Microlending Lost Its Way and Betrayed the Poor (Berrett-Koehler Publishers, San Francisco, 2012).

35 Maryann Bylander, "Credit as coping: rethinking microcredit in the Cambodian context", Oxford Development Studies, vol. 43, núm. 4, p. 546.

36 Le microcrédit au Maroc: quand les pauvres financent les riches, ATTAC/CADTM, 2017.

37 A/HRC/40/57/Add.2, párrs. 78 a 80.

38 Philip Mader, "The Instability of Commercial Microfinance: Understanding the Indian Crisis with Minsky", en Bateman y otros, The Rise and Fall of Global Microcredit, cap. 10.
} 
Durante la visita que realizara a Sri Lanka en 2018 tuve conocimiento de la cantidad, la frecuencia y la gravedad de los abusos de los prestamistas, que afectaban a las mujeres sobre todo. Por ello recomendé al gobierno, entre otras cosas, que ampliara la legislación vigente por la que se regían las licencias microfinancieras, para que todas las instituciones crediticias estuvieran reglamentadas y se declararan nulos (o anulables) los microcréditos abusivos; que velara por que los necesitados dispusieran de programas de alivio de la deuda, y que reconociera a las víctimas el derecho a solicitar la devolución del dinero por concepto de indemnización ${ }^{39}$.

\section{B. Deuda sanitaria}

La deuda sanitaria - que ocasiona una inseguridad financiera y un empobrecimiento crecientes en muchos hogares del mundo, debido a la necesidad de servicios de maternidad, a una hospitalización imprevista, a una enfermedad crónica, a la necesidad de medicamentos caros o raros o al uso frecuente de servicios e instalaciones - suele deberse a unos gastos médicos directos elevados que las personas no se pueden costear. Tales gastos exponen, cada vez más, a las personas al riesgo de sufrir dificultades financieras; según los cálculos mundiales, unos 33 millones de personas afrontan cada año problemas financieros por tener que pagar intervenciones quirúrgicas básicas directamente de su bolsillo, lo que las empuja a la pobreza ${ }^{40}$.

El factor primario al que obedecen los elevados gastos directos es la falta de acceso a una atención, unos servicios o unas instalaciones esenciales de salud adecuados: más del $50 \%$ de la población mundial carece de acceso a una atención sanitaria esencial y, en la mayoría de los países, la accesibilidad y la asequibilidad de esta atención son reducidas o no están

\footnotetext{
39 A/HRC/40/57/Add.2, párr. 97.

40 OIT, Protección social universal para la dignidad humana, la justicia social y el desarrollo sostenible, Conferencia Internacional del Trabajo, 108ª reunión, Ginebra, 2019, p. 111.
} 
garantizadas. En muchos países, los planes de salud pueden cubrir muy pocas intervenciones, no cubrir los medicamentos $\mathrm{u}$ ofrecer una protección financiera insuficiente ${ }^{41}$; el seguro de salud no protege necesariamente a los asegurados contra las deudas médicas.

Parece que, por ejemplo, en Estados Unidos una de cada tres personas afirma tener dificultades para pagar sus gastos médicos, a pesar de que muchas de las que registran deudas médicas están aseguradas ${ }^{42}$. A menudo, los asegurados deben efectuar gastos muy elevados en coberturas deducibles, copagos y otros cargos, que en ocasiones no se pueden permitir ${ }^{43}$.

El gasto médico catastrófico se adjudica también a la existencia de prácticas de medicina privada no reglamentadas ni organizadas en algunos países ${ }^{44}$. La implantación de un régimen sanitario universal adecuado y la asignación de fondos y recursos públicos suficientes pueden ser medios decisivos para reducir los elevados gastos médicos directos y, por tanto, la pobreza y el endeudamiento por motivos de salud.

La deuda sanitaria puede tener consecuencias de largo plazo y muy destructivas para lxs deudorzs particulares, con independencia de que se deba a una única intervención o a un gasto corriente necesario para sobrevivir. Las personas que tienen una deuda médica se hallan en una situación particularmente vulnerable, ya que suelen haber perdido su fuente de ingresos, a causa de una enfermedad o de lesiones. Los hogares endeudados pueden vender sus bienes o solicitar más

\footnotetext{
41 Ibid.

42 Karen Pollitz y otros, "Medical Debt among People with Health Insurance", Henry J. Kaiser Family Foundation, 2014.

43 David Bank y Jenny Griffin, “Financing Out-of-Pocket Medical Debt and Keeping Bill Collectors at Bay", Aspen Institute, 2015.

44 Wim Van Damme y otros, "Out-of-pocket health expenditure and debt in poor households: evidence from Cambodia", Tropical Medicine and International Health, vol. 9, núm. 2, p. 278; Organización Mundial de la Salud (OMS), "India tries to break cycle of health-care debt", Boletín de la OMS, vol. 88, núm. 7, 2010.
} 
empréstitos para amortizar esa deuda, con lo cual caen en la trampa del endeudamiento y, por ende, en la de la pobreza.

La falta de alimentos, la insuficiencia de alimentos nutritivos, la malnutrición y el hambre perjudican gravemente la salud física de las personas, sobre todo la de los niños, las embarazadas, los enfermos crónicos y las personas de edad. Para quienes se hallan en situación de mora en sus pagos o de impago, las facturas y el hambre están muy ligados, lo que los obliga, en ocasiones, a solicitar "préstamos avalados por el cobro del próximo salario" y ayuda alimentaria. El Relator Especial sobre la extrema pobreza y los derechos humanos ha comprobado que el recurso a los bancos de alimentos casi se cuadruplicó entre 2012-2013 y 2017-2018 y que actualmente hay más de 2.000 bancos de alimentos en el Reino Unido, cuando no había más que 29 en el apogeo de la crisis financiera ${ }^{45}$.

En algunas partes del mundo, quienes no están en condiciones de pagar su deuda médica pueden quedar recluidos en centros médicos (públicos o privados). Sigue sin conocerse la magnitud de esta práctica, pero de la escasa investigación ecdémica que se ha hecho al respecto se deduce que probablemente haya centenares de miles de afectadxs al año. En concreto, se ha observado que en diversos países se impone la "reclusión médica" por el impago de facturas médicas ${ }^{46}$.

La deuda privada de los hogares resultante de gastos de salud suele acrecentar los ingresos de los agentes privados, que convierten el acceso a la atención de la salud y los medicamentos en una mercancía y un modelo de negocio sumamente rentables. El costo de los medicamentos esenciales, cuando no está regulado por el Estado o se encuentra protegido por patentes y negociaciones secretas y se halla, por tanto, librado

\footnotetext{
45 A/HRC/41/39/Add.1, párr. 22.

46 Se ha observado esta práctica en el Camerún, Ghana, Kenya, la India, Indonesia, Liberia, Nigeria, la República Democrática del Congo, Uganda y Zimbabwe; véase Robert Yates, Tom Brookes y Eloise Whitaker, "Hospital Detentions for Non-payment of Fees: A Denial of Rights and Dignity", Research Paper, Centre on Global Health Security, 2017.
} 
a las "fuerzas del mercado", es una de las causas principales del incremento de la deuda sanitaria y un grave problema desde la perspectiva de los derechos humanos ${ }^{47}$.

\section{Deuda educativa}

Millones de hogares de todo el mundo adoptan decisiones difíciles sobre la educación de lxs niñxs y los adolescentes, que se suelen basar en consideraciones económicas y en su dependencia total del acceso al crédito. En algunos casos, los hogares tienen que escoger qué miembro de la familia "merece" más una educación, lo que, en ocasiones, significa solo el primogénito, o el hijo y no la hija. Pese a que los Estados tienen la obligación de ofrecer enseñanza pública gratuita, 262 millones de jóvenes de edad comprendida entre los 6 y los 17 años seguían sin escolarizar en 2017 y más de la mitad de lxs niñxs y los adolescentes no reunían los requisitos mínimos de competencia en lectura y matemáticas ${ }^{48}$.

El reclamo de que se prevenga el riesgo de endeudamiento excesivo obedece a una situación que se agrava en todo el mundo, y también puede referirse, con frecuencia, al endeudamiento para sufragar los gastos de la enseñanza secundaria. También han aumentado los préstamos estudiantiles, dado que se han impuesto medidas de austeridad en el sistema de educación pública de muchos países, se han expandido las escuelas privadas y ha subido rápidamente el costo de la educación ${ }^{49}$. Como ha subrayado la Relatora Especial sobre el derecho a la educación, las escuelas que tienen fines de lucro pueden intentar aumentar lo máximo posible sus beneficios cobrando tasas elevadas o recortar gastos reduciendo las partes más caras del plan de estudios, expulsando a lxs alumnxs que necesitan

\footnotetext{
47 Véase https://msfaccess.org/secret-medicine-prices-cost-lives.

48 Véase $\mathrm{A} / \mathrm{HRC} / 41 / 37$.

49 Michael Lim, Mah Hui y Jomo Kwame Sundaram, “Transforming Society, Financialization Destroys Social Solidarity", Inter Press Service, 4 de junio de 2019.
} 
más apoyo o no manteniendo debidamente las instalaciones escolares $^{50}$.

Los préstamos estudiantiles para sufragar la enseñanza superior se suelen considerar una inversión positiva y una "deuda buena”, ya que pueden ayudar a obtener mejores calificaciones académicas y oportunidades de empleo y ofrecer una estabilidad financiera a una persona y a toda su familia. Sin embargo, los datos empíricos consultados indican que esos préstamos ya no garantizan la movilidad social ni la estabilidad financiera. La concentración cada vez mayor del mercado laboral y la parálisis del incremento salarial hacen que lxs graduadxs suelan tener dificultades para encontrar un empleo que les permita amortizar la deuda ${ }^{51}$.

En Fiji, se prevé que lxs estudiantes que reciban préstamos del Plan de Préstamos para la Enseñanza Superior destinen a amortizarlos el $20 \%$ del sueldo bruto que perciban cuando obtengan empleo ${ }^{52}$. En Tailandia, para favorecer el acceso a las enseñanzas secundaria y superior de lxs hijxs de familias de ingresos bajos, el gobierno recurrió a un fondo especial para conceder préstamos a 2,9 millones de beneficiarios de 1996 a $2007^{53}$; sin embargo, hubo casos de dificultades de amortización e impago de deudas, debido, por ejemplo, a problemas económicos derivados del desempleo ${ }^{54}$. En Chile, en la universidad, el interés de los préstamos estudiantiles ha subido al $6 \%$, con lo

\footnotetext{
50 Ibid.

51 Michael Corkery y Stacy Cowley, "Household Debt Makes a Comeback in the U.S.", New York Times, 17 de mayo de 2017.

$52 \mathrm{~A} / \mathrm{HRC} / 32 / 37 /$ Add.1, párr. 39.

53 Piruna Polsir y otros, "Thailand's Student Loans Fund: An analysis of interest rate subsidies and repayment hardships", en Shiro Armstrong y Bruce Chapman, Financing Higher Education and Economic Development in East Asia (Australian National University press, Canberra, 2011), p. 221.

54 Amara Tirasriwat, "Analysis of Problems on Student Loan Defaults in Thailand and Guideline Solutions", XIV Conferencia Internacional sobre Empresas y Economía, Bangkok, 5 a 8 de enero de 2015.
} 
cual los prestatarios pueden tardar décadas en amortizarlos ${ }^{55}$. Se sabe que los grupos más vulnerables tienen dificultades para pagar sus deudas y que las personas más afectadas son específicamente las que acuden a escuelas técnicas superiores y universidades ${ }^{56}$.

\section{Deudas de vivienda y servicios públicos}

La financierización de la vivienda, los préstamos abusivos y la deuda hipotecaria impagable de los hogares, que fueron las causas primarias de la crisis financiera de 2008, ilustran la relación que hay entre la deuda de los hogares y la liberalización de los mercados financieros, que van en detrimento de la población y tienen consecuencias devastadoras en forma de miles de ejecuciones hipotecarias, desalojos generalizados, desplazamientos y falta de hogar en los países del Norte y cada vez más en los del Sur globalizado. La Relatora Especial sobre el derecho a una vivienda adecuada ya en 2012 había advertido acerca de las prácticas de concesión de préstamos leoninos a las personas en situación de pobreza y más marginadas, que conducían a éstas a la trampa del endeudamiento como única posibilidad de procurarse una vivienda, y acerca del hecho de que los Estados, en ocasiones, de hecho favorecían ese proceso y, en otras, hacían caso omiso de los riesgos que ello entrañaba para la población y la economía en general ${ }^{57}$.

En 2017, la Relatora Especial sobre derecho a una vivienda adecuada señaló también que la financierización de la vivienda estaba relacionada con la ampliación del crédito y la deuda contraída por los hogares vulnerables a las prácticas de concesión de préstamos leoninos y con la inestabilidad de los mercados, y que el resultado de ello era la "precariedad" sin

\footnotetext{
55 Comunicación del Comité de Abolición de la Deuda del Tercer Mundo.

56 Véase Macarena Segovia, "Las cifras negras del CAE: 40 \% de los estudiantes desertores o egresados se encuentran morosos", El Mostrador, 28 de mayo de 2018.

57 Véase $A / 67 / 286$.
} 
precedentes de la vivienda. Resumió la situación en estos términos: "La gente no solo perdió su casa sino que también tuvo que hacer frente a la ruina financiera personal" 58 .

Dado que la vivienda es el punto de partida del ejercicio de numerosos derechos humanos, como los relativos a la educación, el trabajo o la salud, las personas suelen considerar los gastos de alquiler, hipotecas o servicios públicos como prioridades familiares absolutas, frecuentemente para su propio riesgo. Ello contradice directamente la interpretación autorizada sobre los gastos soportables en relación con el derecho a la vivienda que formuló el Comité de Derechos Económicos, Sociales y Culturales en su Observación General núm. 4 (1992), en la que aclaró que los gastos personales o del hogar que entrañaba la vivienda deberían ser de un nivel que no impidiera ni comprometiera el logro y la satisfacción de otras necesidades básicas. El Comité añadió que los Estados partes deberían crear subsidios de vivienda para los que no pudieran costearse una, así como formas y niveles de financiación que correspondieran adecuadamente a las necesidades de vivienda. Es esencial señalar que la discriminación que practican los arrendadores públicos y privados, así como los proveedores de crédito, por diversos motivos, como la orientación sexual, tiene repercusiones importantes, pues, por ejemplo, se deniegan solicitudes de alquiler e hipoteca a personas lesbianas, gays, bisexuales, transgénero e intersexuales ${ }^{59}$.

Otro problema específico es el de las hipotecas contratadas en moneda extranjera por personas que ya tienen dificultades previas para pagar sus deudas, hipotecas que en ocasiones perjudican a los deudores o sus "posibilidades" de refinanciación y que suelen ser promovidas de manera entusiasta por los prestamistas ${ }^{60}$.

\footnotetext{
58 A/HRC/34/51, párrs. 5 y 21.

59 Comité de Derechos Económicos, Sociales y Culturales, observación general núm. 20 (2009), relativa a la no discriminación y los derechos económicos, sociales y culturales, párr. 11; véanse también $\mathrm{A} / 74 / 18$, párr. 14, y A/HRC/29/23, párr. 69.

60 Véase la comunicación de la Iniciativa Projusticia de la Sociedad Abierta y otros, Rumania e Irlanda.
} 
Las fluctuaciones del mercado inmobiliario pueden tener consecuencias nefastas para los deudores. En Noruega, la expansión de ese mercado influyó en el endeudamiento de los hogares entre 1997 y $2007^{61}$. Además, no debería dejarse fuera de la ecuación de la vivienda adecuada la actividad que realizan los fondos buitre que adquieren las deudas de los prestamistas y, en ocasiones, los hogares de los deudores y que, además, gozan de ventajas fiscales ${ }^{62}$.

En 20 años, 20 millones de personas se han mudado a las zonas periurbanas en México, zonas donde las personas en situación de pobreza carecen de abastecimiento de agua o de infraestructuras suficientes, y la construcción de 5 millones de viviendas sociales lejos de los núcleos urbanos y su venta a familias pobres, mediante planes de financiación a largo plazo, ha dejado a estas atrapadas, pues deben pagar una nueva vivienda que carece de servicios básicos de abastecimiento de agua y demás servicios públicos básicos. Dado que los promotores inmobiliarios tenían garantizados ciertos beneficios, gracias a una financiación sin riesgos proporcionada por el gobierno mediante el cobro de un impuesto del $5 \%$ a todxs lxs trabajadorxs ${ }^{63}$, este mercado financiero se convirtió rápidamente en el más titulizado de toda América Latina ${ }^{64}$. Los promotores inmobiliarios, en defecto de una reglamentación adecuada, eligieron los terrenos más baratos, con lo que se procuraron unos márgenes de beneficio de hasta el $40 \%{ }^{65}$.

Los desastres naturales también pueden influir en el endeudamiento de los hogares. En Puerto Rico, se hizo un estudio un año después del huracán María (2017), en el que se observó

\footnotetext{
61 Unidad de Inteligencia de The Economist, "Household debt poses risk to private consumption", 30 de julio de 2019.

62 Comunicación de la Iniciativa Projusticia de la Sociedad Abierta y otros.

63 Comunicación de Greene, Peixoto-Charles y Morvant-Roux.

64 Susanne Soederberg, "Subprime housing goes south: Constructing securitized mortgages for the poor in Mexico", Antipode, vol. 47, núm. 2.

65 Comunicación de Greene, Peixoto-Charles y Morvant-Roux.
} 
que los damnificados por el desastre padecían, por lo común, "dificultades financieras": el $17 \%$ de loxs entrevistadxs declararon que se habían retrasado en los pagos del alquiler o de la hipoteca; el $24 \%$ también mencionaron que habían tenido que pedir prestado dinero a sus amigos y familiares "para llegar a fin de mes" durante ese año ${ }^{66}$. También se ha señalado que, después de las inundaciones que hubo en el Pakistán en 2010, lxs agricultorxs vieron cómo se duplicaba o incluso triplicaba su deuda y tuvieron que recurrir a los empréstitos para procurarse insumos agrícolas y alimentos ${ }^{67}$. Habida cuenta de que la tierra sirve ocasionalmente de garantía de los préstamos contratados por lxs pequeñxs agricultorxs, éstos corren un claro peligro de perder sus medios de subsistencia en caso de impago de una deuda cuando se produce un desastre natural, la cosecha es mala o bajan los precios de los productos primarios ${ }^{68}$, a pesar de que deberían estar protegidos en tales situaciones con arreglo a la Declaración de las Naciones Unidas sobre los Derechos de los Campesinos y de Otras Personas que Trabajan en las Zonas Rurales.

\section{E. Prácticas coactivas y abusivas de cobro de deudas y criminalización de los deudores}

Los prestamistas pueden recurrir a diversos medios o procedimientos coactivos para que se les paguen las deudas contraídas con ellos. Además del procedimiento de apremio judicial, en caso de que la deuda se haya contraído legalmente, con frecuencia recurren a los servicios de cobro de deudas, que van desde "agencias oficiales" hasta instituciones no financieras. Se han denunciado casos de deudorxs que han sufrido llamadas

\footnotetext{
66 Bianca DiJulio, Cailey Muñana y Mollyann Brodie, "Views and experiences of Puerto Ricans One Year after Hurricane Maria", Washington Post/Kaiser Family Foundation, septiembre de 2018, p. 12.

67 Véase Organización de las Naciones Unidas para la Alimentación y la Agricultura, “The impact of natural hazards and disasters on agriculture, and food security and nutrition", Roma, 2015.
}

68 A/HRC/13/33/Add.2, párr. 26. 
telefónicas diarias u otras formas de acoso y prácticas vergonzosas por parte de los cobradores de deudas. En otros casos, se ha denunciado que los cobradores confiscan las tarjetas de crédito de los deudores para que estos retiren la suma adeudada (más los intereses) en un cajero automático ${ }^{69}$. En Sri Lanka, se han denunciado prácticas como la de los cobradores que van a casas de mujeres deudoras y se quedan allí durante horas hasta que se les pague o la de los cobradores que ejercen violencia psicológica y física sobre las mujeres ${ }^{70}$.

En Chequia, se considera que alrededor del $10 \%$ de la población es objeto de "cobro coactivo de deudas", cuya repercusión en la pobreza y las privaciones es una manifestación particular de la desigualdad de ingresos ${ }^{71}$. El efecto exponencial de la acumulación de deuda, unido ocasionalmente al de unos tipos de interés elevados, puede obligar a las personas a buscarse un empleo informal o infundirles el temor de que se les quite una parte considerable de su sueldo ${ }^{72}$ y les quede poco para satisfacer sus necesidades básicas. Cabe señalar también la posible influencia del fenómeno en la "economía paralela" y las corrientes financieras ilícitas.

En Sudáfrica, el cobro de deudas es un "sector" de importancia considerable; por ejemplo, los tribunales dictaron 18.973 sentencias por deudas cuyo valor total era de 342,1 millones de rands solo en mayo de $2019^{73}$. En este breve período se emitió la escalofriante cifra de 47.360 citaciones por deudas.

El endeudamiento excesivo puede privar a las personas endeudadas no solo de sus derechos económicos, sociales y

\footnotetext{
69 Deborah James, "'Deeper into a hole?': borrowing and lending in South Africa", Current anthropology, vol. 55 (2014), p. 6.

$70 \mathrm{~A} / \mathrm{HRC} / 40 / 57 /$ Add.2.

71 Véase SDG Watch, Falling Through the Cracks: Exposing Inequalities in the EU and Beyond, Bruselas, 2019.

72 Robert Muller, "Debt-trapped Czechs excluded as economy grows", Reuters, 13 de diciembre de 2018.

73 Comunicación del Centro de Asistencia Jurídica de la Universidad de Stellenboch.
} 
culturales, sino también de sus derechos civiles y políticos, pues se las penaliza y sanciona en el sistema de justicia penal. Se ha observado este fenómeno en diversas regiones del mundo. Por ejemplo, en 2014, en Yemen, decenas de personas fueron encarceladas, según parece, por no poder pagar su deuda privada ${ }^{74}$. En Sierra Leona, las deudas por los empréstitos y los préstamos informales obtenidos para realizar pequeñas transacciones comerciales terminan, a menudo, resolviéndose en el sistema de justicia penal, con la detención y el encarcelamiento de los deudores ${ }^{75}$.

Las personas con un historial de ingresos bajos pueden acumular deuda por las multas y los recargos que impongan las autoridades municipales, como multas de tráfico y de aparcamiento. Estas sumas se pueden acrecentar rápidamente cuando dichas personas entran en el sistema judicial y afrontan gastos adicionales ${ }^{76}$.

En el caso de las personas en situación de vulnerabilidad, la acumulación de multas y recargos, que también se puede deber a distintas formas de discriminación, puede tener consecuencias graves y, en ocasiones, acabar en unas sumas que, en definitiva, esas personas no estén en condiciones de pagar. En 2009, en un estudio canadiense realizado en Montreal se llegó a la conclusión de que, en comparación con la generalidad de la población, a las personas sin hogar se les imponía una cantidad desproporcionada de multas por delitos leves; el impago de las multas podía entrañar su detención ${ }^{77}$.

Para las personas en situación de pobreza y vulnerabilidad, el acceso a la justicia puede ser particularmente difícil. Según el Relator Especial sobre la extrema pobreza y los derechos humanos,

\footnotetext{
74 Human Rights Watch, "Yemen: Dozens Jailed for Debts", 21 de abril de 2014.

75 Alison Thompson y Sabrina Mahtani, "Women, Debt \& Detention: An Exploratory Report on Fraudulent Conversion and the Criminalisation of Debt in Sierra Leone", AdvocAid, julio de 2012

76 The Aspen Institute, "Consumer debt: A Primer", marzo de 2018, p. 21.

77 Christine Campbell y Paul Eid, "La judiciarisation des personnes itinerantes à Montréal: un profilage social", Commission des droits de la personne et des droits de la jeunesse, 2009
} 
además de los costes de la asistencia de defensa letrada, existen numerosos costes relacionados con el acceso a la justicia que constituyen una barrera importante para aquellxs en situación de pobreza, que simplemente no pueden permitirse tales gas$\operatorname{tos}^{78}$. Pueden tener gastos indirectos de presentación de documentos, transporte o peritajes, o perder ingresos por acudir a los tribunales, lo que también puede contribuir, en definitiva, a que el hogar se endeude.

\section{F. Deuda de los consumidores}

El crédito al consumo comprende las deudas amortizables a plazos y el crédito regular (renovable). Estas deudas se pueden contraer de diversas maneras: mediante el gasto en alimentos básicos, educación, servicios de salud y medicamentos o mediante los gastos de celebración de una fiesta nacional o religiosa o la compra de artículos no esenciales, el juego de apuestas o los juegos de Internet.

El acceso al crédito por medio de los cauces oficiales sigue siendo un problema importante para muchos grupos, sobre todo para aquellos que se hallan en situación de vulnerabilidad o marginalidad. En algunos países, el ofrecimiento constante a los consumidores de nuevas "oportunidades", presiones y prácticas para que contraten préstamos, como las tarjetas de crédito no solicitadas o la publicidad financiera mediante aplicaciones para teléfonos móviles, también puede contribuir a la deuda de los hogares y al endeudamiento excesivo.

Por ejemplo, en la Argentina, en 2019 más de 7,7 millones de jubilados y otras personas legitimadas para percibir una asignación universal por hijo deben aproximadamente 3.000 millones de dólares a la administración nacional de la seguridad social. La desaceleración económica, caracterizada por una deuda pública ingente y por el descenso de los salarios, también ha llevado a la bancarrota a muchxs beneficiarixs de

78 A/67/278, párr. 51. 
la seguridad social en los últimos cuatro años, millones de los cuales se han visto obligadxs a solicitar créditos a la administración de la seguridad social para pagar los bienes y servicios esenciales. La cifra de personas que tienen una deuda con la seguridad social llega hasta el $30 \%$ del total de jubilados (más de 2,1 millones de personas) y hasta el $95 \%$ de los beneficiarios de la asignación universal por hijo. Se calcula que un $80 \%$ de estos beneficiarios no podrían permitirse pagar la canasta básica: los gastos básicos de subsistencia y alimentación, una vez restada la deducción tributaria del $30 \%$.

Como ha subrayado la Comisión Sudafricana de Derechos Humanos, las personas más vulnerables a las violaciones contra los derechos humanos resultantes de prácticas financieras abusivas son las pertenecientes a los grupos de ingresos bajos y las que viven en la pobreza. Cabe señalar que, en Sudáfrica, el total de los créditos concedidos a lxs consumidorxs subió de alrededor de 17 millones en 2007 a 24 millones en 2016. Además, se calcula que al menos el $40 \%$ de los ingresos mensuales de lxs trabajadorxs se destinaba a amortizar deudas ${ }^{80}$ y que alrededor del $80 \%$ del sueldo de quienes trabajaban en el sector formal estaba sujeto a deducciones por deudas contraídas en $2012^{81}$. Se ha sabido que, en algunas partes de Rusia, la población a veces tenía dificultades para llegar a fin de mes, ya que destinaba hasta un $83 \%$ de su sueldo mensual a amortizar préstamos ${ }^{82}$.

El endeudamiento excesivo de los consumidores puede repercutir de diversas maneras en los derechos humanos. Por ejemplo, en una serie de entrevistas sobre los efectos del endeudamiento excesivo realizadas en Alemania, Eslovenia,

\footnotetext{
79 David Cufré, "Reperfilar al jubilado", Página/12, 28 septiembre de 2019.

80 Comisión Sudafricana de Derechos Humanos,"Human Rights Impact of Unsecured Lending and Debt Collection Practices in South Africa", 2017, pags. 7 y 14.

81 Véase Chantelle Benjamin, "Garnishee abuse is order of the day", Mail\&Guardian, 25 de octubre de 2013.

82 Max Seddon, "Russians struggle under burden of soaring consumer loans", Financial Times, 29 de agosto de 2019.
} 
España, Francia, Hungría y el Reino Unido se indicó que los efectos más comunes eran la disminución del nivel de vida y el empeoramiento del bienestar o de la salud mental ${ }^{83}$.

La consideración de una persona como mal pagador, por causa de atrasos o impagos de deudas, puede tener consecuencias graves: un mal historial crediticio suele tener repercusiones morales y económicas. Algunos deudores han destacado la carga psicológica y la vergüenza que entraña ser considerado mal pagador y otros han destacado las consecuencias que puede tener en sus medios de subsistencia y en su empleo.

Paralelamente a las formas de crédito más tradicionales, el sector del crédito digital evoluciona con celeridad y ofrece servicios a una cantidad creciente de prestatarios. En Kenya, el $70 \%$ de los adultos usan actualmente dinero móvil y solo el $40 \%$ tienen una cuenta bancaria ${ }^{84}$. La información personal obtenida por el sector tecnofinanciero (fintech), sobre todo mediante las aplicaciones de pago y préstamo, es otro asunto preocupante. Como los prestamistas creen que todos los datos son "datos de crédito", aplican algoritmos complejos de gestión de macrodatos que procesan la actividad que mantienen millones de personas en los medios sociales, para intentar evaluar su solvencia crediticia ${ }^{85}$. Estas prácticas también pueden afectar a las personas de maneras que van más allá de consideraciones económicas.

Por otra parte, la tecnología del sector financiero favorece de manera creciente (y poderosa) la gestión del crédito por medios digitales, sobre todo las aplicaciones móviles, lo que conduce al endeudamiento excesivo ${ }^{86}$. Es este un sector sumamente libera-

\footnotetext{
83 European Consumer Debt Network, "The over-indebtedness of European households", 6 de noviembre de 2014.

84 Eric Toussaint, "Alert on the sophistication of illegitimate debt techniques via mobile telephony", CADTM, 8 de noviembre de 2019.

85 Kevin Donovan y Emma Park, "Perpetual Debt in the Silicon Savannah", Boston Review, 20 de septiembre de 2019.

86 Véase Milford Bateman y otros, "Is fin-tech the new panacea for poverty alleviation and local development? Contesting Suri and Jack's M-Pesa findings published in Science", Review of African Political Economy, vol. 46, núm. 161 (2019).
} 
lizado. En varios países africanos se han concedido préstamos avalados por el cobro del próximo salario con unos tipos de interés del $100 \%{ }^{87}$. Dado ese contexto, se estima que las políticas y las entidades que tienen por objetivo defender los derechos de lxs consumidorxs y que ofrecen "formación financiera" desempeñan una función fundamental de mitigación de las posibles repercusiones que tengan el endeudamiento excesivo y las prácticas abusivas de concesión de préstamos en los derechos humanos.

Cuando muchos prestatarios obtienen varios préstamos de corto plazo al mismo tiempo, suelen necesitar más crédito para amortizar el préstamo anterior, lo que, en la práctica, acaba convirtiendo los préstamos de corto plazo en préstamos de largo plazo, con unos tipos de interés muy altos.

\section{G. Deuda migratoria}

Se puede contraer una deuda migratoria para pagar los gastos de emigración a otro país, con o sin documentos. La deuda puede incluir el pago de la documentación, el viaje por diversos medios, la ayuda para cruzar fronteras o incluso sobornar a las autoridades durante el tránsito o pagar a los traficantes cuando se emigra sin documentación. Esta deuda suele ser un problema para toda la familia (extensa) y crea vínculos y obligaciones entre los familiares de mayor y de menor edad.

Aunque la migración de Centroamérica y América del Sur a los Estados Unidos es una realidad bien documentada, el incremento de los controles fronterizos y de las prácticas crueles, como la detención de lxs niñxs no acompañadxs que se ha registrado en los últimos años, ha centrado la atención en sus complejidades y en la red financiera subyacente. Es evidente que políticas migratorias más estrictas elevarán el precio (y la deuda) que tendrán que pagar lxs migrantes a quienes los ayudan a viajar.

87 Comisión Sudafricana de Derechos Humanos, “Human Rights Impact of Unsecured Lending", p. 17. 
Cuanto más se endeuda un miembro de una familia por causa de la migración económica, más probable es que caiga en un círculo vicioso de endeudamiento alimentado por la esperanza de evitar perder la fianza. La presión psicológica y física, el acoso sexual, las amenazas de muerte y otros medios para intimidar a los familiares que se quedan en el país de origen forman parte, con frecuencia, de los abusos que cometen los cobradores y los traficantes. La presión que se ejerce sobre esas personas puede incluso llevarlas al suicidio. Habida cuenta de que un terreno que es esencial para el sustento de la familia o una casa suelen aportarse como caución de un préstamo, las víctimas no solo caen en el endeudamiento excesivo sino que también se ven despojadas de los exiguos recursos que disponían.

Con cada intento, aumentan los peligros y las amenazas, y las redes de tráfico (incluidos los "coyotes" y otros traficantes), que a veces cuentan con la complicidad de las fuerzas de seguridad fronterizas, sacan provecho económico. Así pues, personas y familias buscan fuera de su red de contactos y obtienen préstamos con intereses elevados de agentes institucionales no reglamentados o laxamente reglamentados, como prestamistas, notarios, cooperativas o bancos, en garantía de los cuales aportan terrenos, casas, vehículos u otros bienes ${ }^{88}$. Dada la situación, algunos considerarían que la única solución para amortizar esas deudas es la migración de retorno.

Resulta tristemente paradójico que muchxs de quienes emigran por necesidad económica suelen ser abandonadxs por sus Estados. En cambio, esas personas envían remesas a su país de origen y ayudan muchísimo a sostener la economía. En Guatemala, las remesas de fondos representaron en 2017 más del $11 \%$ del PIB y más que la inversión extranjera directa en el país ${ }^{89}$.

Incluso en el caso de la migración oficial, algunos países no permiten a los inmigrantes recientes trabajar durante un período,

88 Laura Heidbrink, "The coercive power of debt: migration and deportation of Guatemala indigenous youth", The Journal of Latin America and Caribbean Anthropology, vol. 24, núm. 1 (2019).

89 IMF Country Report núm. 18/155, junio de 2018, p. 5. 
lo que agrava su situación económica familiar en un momento en el que tienen que amortizar sus deudas migratorias. Además, los refugiados y los solicitantes de asilo pueden contraer nuevas deudas al llegar a un país, ya que tienen dificultades económicas varias para satisfacer sus necesidades básicas. Por ejemplo, en 2018, el $88 \%$ de los hogares de refugiadxs sirixs del Líbano tenían deudas ${ }^{90}$.

La situación no es muy distinta en el Asia Sudoriental, donde en los últimos años ha aumentado la preocupación por el endeudamiento excesivo de lxs migrantes. La Organización Internacional para las Migraciones ha puesto de relieve ciertas dinámicas específicas, como el incremento del recurso a la deuda para financiar los gastos migratorios; la existencia de tasas elevadas de deuda del hogar entre las familias que envían migrantes; el surgimiento de nuevas formas de migración desesperada provocadas por el endeudamiento excesivo; el grado en que las remesas de fondos y las ganancias de los migrantes se destinan al pago de préstamos, y las secuelas emocionales y psicológicas del endeudamiento de lxs migrantes ${ }^{91}$.

\section{H. Servidumbre por deudas}

Millones de personas de todas las regiones del mundo siguen estando sujetas a servidumbre laboral o por deudas, una forma de explotación de seres humanos que roza la esclavitud y, a menudo, es una esclavitud propiamente dicha. En 2016, la servidumbre por deudas afectaba a la mitad de las víctimas de trabajo forzoso impuesto por agentes privados en todo el mundo ${ }^{92}$; además, se calcula que 4,8 millones de los

90 Oficina del Alto Comisionado de las Naciones Unidas para los Refugiados, "Yearly UN Study: Syrian Refugees in Lebanon Accumulated More Debt in 2018 than Ever before", 26 de diciembre de 2018.

91 Organización Internacional para las Migraciones, Debt and the Migration Experience: Insights from South-East Asia, 2019, p. 15.

92 OIT, Estimaciones mundiales sobre la esclavitud moderna: Trabajo forzoso y matrimonio forzoso, Ginebra, 2017, p. 5. 
24,9 millones de víctimas de trabajo forzoso eran explotadas sexualmente ${ }^{93}$.

Según la Relatora Especial sobre las formas contemporáneas de la esclavitud, la servidumbre por deudas aparece en diversos sectores de la economía y pesa, de manera desproporcionada, sobre quienes se hallan en situación de vulnerabilidad, como los miembros de grupos minoritarios, la población indígena, las mujeres, lxs niñxs, las personas consideradas de casta inferior y lxs trabajadorxs migrantes. Ha comprobado que muchas víctimas de servidumbre por deudas sufren discriminación por motivos múltiples e interseccionales, lo que las vuelve vulnerables a la explotación y los abusos. La Relatora Especial ha señalado que los trabajadores migrantes representan una proporción significativa de la fuerza de trabajo en la Arabia Saudita, Bahrein, los Emiratos Árabes Unidos, Kuwait, Omán y Qatar, países pertenecientes al Consejo de Cooperación del Golfo, sobre todo en el sector privado, donde el sistema de la kafala, que permite a lxs empleadorxs patrocinar a lxs trabajadorxs, es campo abonado para la dependencia y para posibles abusos y servidumbre por deudas, porque supedita el empleo y la residencia de lxs trabajadorxs a sus empleadorxs ${ }^{94}$.

Las agencias de empleo suelen cobrar gastos y honorarios ilegales cuando contratan trabajadorxs extranjerxs. Se han denunciado casos de confiscación de documentos de identidad por parte de las agencias hasta que lxs trabajadorxs paguen sus deudas completamente ${ }^{95}$. Se considera que estas prácticas favorecen la servidumbre por deudas ${ }^{96}$, así como el impago del salario, el pago incompleto o la demora en el pago de éste y la sustitución del contrato. Debido a la presión que ejercen las agencias de empleo para firmar nuevos contratos de trabajo,

\footnotetext{
93 Ibid., p. 10.

94 A/HRC/33/46, párrs. 9 y 29.

95 Comunicación del Foro de Asia y el Pacífico sobre la Mujer, el Derecho y el Desarrollo.

$96 \mathrm{~A} / \mathrm{HRC} / 33 / 46$.
} 
a veces se rescinde sin miramientos el contrato de lxs trabajadorxs domésticxs en cuanto éstos amortizan finalmente su deuda y empiezan a recibir un salario ${ }^{97}$.

\section{Deuda de los hogares y estándares de derechos humanos}

El auge de la deuda privada de los hogares en muchos países es resultado directo de dos fenómenos paralelos: el incumplimiento por parte de los Estados de sus obligaciones de derechos humanos, sobre todo en el ámbito de los derechos económicos, sociales y culturales, y la financierización y la mercantilización crecientes de los servicios sociales.

Las normas de derechos humanos se basan fundamentalmente en la idea de que los Estados (y en cierta medida los agentes privados) tienen la obligación de respetar, proteger y hacer efectivos estos derechos garantizando la igualdad y luchando contra la discriminación. La proclamación de que todos los seres humanos son iguales en dignidad y derechos es la disposición por antonomasia de la Declaración Universal de Derechos Humanos.

La financierización puede constituir, en la práctica, la antítesis de la citada norma, ya que descansa en la idea de que incumbe al individuo tomar las medidas apropiadas para procurarse un nivel de vida adecuado y acceder a los bienes y servicios esenciales. El creciente acceso de todxs al crédito, entendido como "inclusión financiera", se considera cada vez más como una solución a muchos problemas de derechos humanos, ya sea el abrir un negocio o montar una empresa para ganarse la vida o el procurarse una atención sanitaria apropiada o posibilidades de empleo. En el decenio de 1990, Muhammad Yunus, que inventó la idea del microcrédito, llegó a afirmar que el acceso al crédito era "un derecho humano básico de todxs"98, aunque no

\footnotetext{
97 Comunicación del Foro de Asia y el Pacífico sobre la Mujer, el Derecho y el Desarrollo.

98 Véase John Gershman y Jonathan Morduch, "Credit is not a right", Microfinance, Rights and Global Justice (Cambridge University Press, Cambridge, 2015), p. 14.
} 
hizo un esfuerzo serio por explicar los fundamentos jurídicos de esa afirmación. La financierización refuerza el poder de los mercados financieros y la idea de la autogestión destinada a mejorar las propias condiciones de vida, lo que difumina la obligación que tienen los Estados de tomar medidas apropiadas para hacer efectivos, de manera progresiva, los derechos económicos, sociales y culturales.

La deuda no es, de por sí, un problema de derechos humanos, y mucho menos una vulneración de estos. La preocupación se suscita cuando el endeudamiento es provocado por violaciones de los derechos humanos o provoca estas vulneraciones, que afectan, sobre todo, a quienes se hallan en una situación de marginación o vulnerabilidad. En la Declaración Universal de Derechos Humanos se reconocen ciertos derechos de particular importancia para analizar el endeudamiento excesivo y las prácticas abusivas de préstamo y cobro, sobre todo los derechos a la vida, la libertad y la seguridad, la libertad de circulación, la seguridad social, una remuneración justa y un nivel de vida adecuado, que incluye la alimentación, la vivienda, la educación, la vestimenta, la atención médica y los servicios sociales necesarios, y el derecho a la seguridad. Los derechos de acceso a la información y a la participación en la vida política y pública también resultan especialmente significativos en este ámbito.

Todos los derechos citados se han consagrado en numerosos instrumentos vinculantes de ámbito internacional, particularmente en el Pacto Internacional de Derechos Económicos, Sociales y Culturales y el Pacto Internacional de Derechos Civiles y Políticos. Por lo que respecta a grupos de población específicos, también se han negociado y ratificado varios instrumentos que garantizan un entendimiento claro de uno de los pilares de los derechos humanos: la no discriminación.

Los principios de igualdad y no discriminación constituyen la médula del derecho internacional de los derechos humanos. La comprensión de las repercusiones que tiene el endeudamiento de los hogares en el ejercicio de derechos como los derechos a 
la salud, la educación, la vivienda o el acceso al agua o la electricidad, lleva ineludiblemente a analizar qué se requiere, desde una perspectiva financiera, para ejercer los derechos humanos. Las personas y los hogares atrapados en la vorágine de la deuda y de la vulnerabilidad económica tienen que enfrentarse con fuerzas o agentes económicos de poder formidable, altos grados de desigualdad, niveles bajos de rendición de cuentas, el incremento de la financierización de los servicios y un acceso limitado a los mecanismos de justicia o de reparación.

Con frecuencia, las personas o los grupos de personas sufren discriminación por su situación económica y social, una discriminación que puede ser directa o indirecta o agravarse a causa de otras formas de discriminación. Este trato arbitrario que sufren se debe a la relación que hay entre su pertenencia a determinado grupo o estrato económico o social dentro de la sociedad y su situación de endeudamiento ${ }^{99}$ y estas personas o grupos pueden ser estigmatizados, marginados o criminalizados por su deuda particular o por la de su hogar ${ }^{100}$.

Hasta cierto punto, los bajísimos niveles de protección social y de gasto público que hay en este campo ${ }^{101}$ y el debilitamiento progresivo de los regímenes de remuneración de lxs trabajadorxs del sector formal constituyen la razón por la que millones de personas recurren al crédito para obtener servicios esenciales y se ven atrapadas en un círculo vicioso. En su Obser-

99 A diferencia de la fianza, la suma abonada por la prima de riesgo (determinada, en su mayor parte, por la disponibilidad y la calidad de la fianza) no se devuelve una vez amortizada la deuda. Esta práctica entraña el cobro de un precio distinto por el mismo producto y, por tanto, una discriminación por razón del patrimonio; véase Oliver Pahnecke, "Interest Rates, Risk Premiums and Human Rights", 2019 (se puede obtener de la secretaría del ACNUDH).

${ }^{100}$ Comité de Derechos Económicos, Sociales y Culturales, observación general núm. 22 (2016), relativa al derecho a la salud sexual y reproductiva (artículo 12 del Pacto Internacional de Derechos Económicos, Sociales y Culturales), párr. 35.

101 Según la Organización Internacional del Trabajo (OIT), solo el 29 \% de la población mundial goza de una seguridad social completa (toda la gama de prestaciones, desde las prestaciones familiares y por hijo a cargo hasta las pensiones de jubilación), mientras que el 71 \% restante goza de protección parcial o carece de toda protección; véase OIT, Informe Mundial sobre la Protección Social 20172019. 
vación General núm. 19, el Comité de Derechos Económicos, Sociales y Culturales se refirió al "carácter redistributivo" de la seguridad social, que desempeña un papel importante de reducción de la pobreza y fomento de la inclusión social. En estrecha relación con lo expuesto se encuentra el derecho al trabajo, que comprende el derecho a una remuneración que proporcione a todxs los trabajadorxs una vida digna para sí y su familia. Como explica el Comité en su Observación General núm. 23, la remuneración debe ser suficiente para permitir al/la trabajador/a y a su familia gozar de otros derechos reconocidos en el Pacto.

La asequibilidad, la accesibilidad y la calidad son elementos esenciales definitorios de los derechos a la vivienda, la salud y la educación ${ }^{102}$. Y, a la inversa, la falta de acceso a los servicios, las instalaciones y los productos de salud obedece, en la mayoría de los casos, a las limitaciones económicas, por una parte (salarios bajos, pobreza, elvados costos de vida, inflación), y al alto precio de los medicamentos, los hospitales y la atención médica, por otra.

La situación no es distinta en el caso del acceso adecuado a la educación pública ${ }^{103}$. A este respecto, en 2019 el Consejo de Derechos Humanos ${ }^{104}$ tomó nota de los Principios de Abiyán sobre las obligaciones de derechos humanos que incumben a los Estados de proporcionar educación pública y regular la participación del sector privado en la educación, con arreglo a los cuales los Estados deben tomar medidas para que ninguna persona quede excluida de un establecimiento educativo público por su incapacidad de costeárselo y deben tomar todas las medidas eficaces necesarias para prevenir el riesgo de endeudamiento excesivo de lxs estudiantes y su familia.

\footnotetext{
102 Comité de Derechos Económicos, Sociales y Culturales, observación general núm. 14 (2000), relativa al derecho al goce del más alto nivel posible de salud, párr. 12 b) iii).

103 Pacto Internacional de Derechos Económicos, Sociales y Culturales, art. 13.2; véase también Comité de Derechos Económicos, Sociales y Culturales, observación general núm. 13 (1999), relativa al derecho a la educación.
}

104 Resolución 41/16. 
En el Pacto Internacional de Derechos Económicos, Sociales y Culturales se reconoce el derecho de toda persona a un nivel de vida adecuado para sí y su familia, incluso alimentación, vestimenta y vivienda adecuados, y a una mejora continua de las condiciones de existencia (art. 11.1). Este artículo debería interpretarse en consonancia con el artículo 2.2 del Pacto, en el que se garantiza el ejercicio de los derechos que se enuncian en dicho instrumento, sin discriminación alguna. Además, en su Observación General núm. 4, el Comité de Derechos Económicos, Sociales y Culturales definió siete características fundamentales del derecho a una vivienda adecuada que deben asegurar los gobiernos.

Además de otras cuestiones graves de derechos humanos que pueden afectar a varios de ellos, como el derecho a la vida, la libertad y la seguridad, hay algunos aspectos del cobro de deudas que plantean cuestiones decisivas en relación con el acceso a la justicia y con los procedimientos y los mecanismos mediante los cuales pueden reclamar deudas tanto los agentes públicos como los privados. En el artículo 26 del Pacto Internacional de Derechos Civiles y Políticos se afirma claramente que todas las personas son iguales ante la ley y tienen derecho sin discriminación a igual protección de la ley.

Los Principios Rectores sobre las Empresas y los Derechos Humanos ${ }^{105}$ reglamentan los efectos que tienen, en los derechos humanos, las actividades empresariales, incluidas las de los agentes bancarios y los agentes crediticios privados del sector financiero, así como las de otros agentes crediticios privados. Según los Principios Rectores, los Estados deben proteger contra las violaciones de los derechos humanos cometidas en su territorio y/o su jurisdicción por terceros, incluidas las empresas. Por otra parte, las empresas no deben vulnerar los derechos humanos y los Estados deben adoptar las medidas apropiadas para prevenir, investigar, castigar y reparar esos abusos

${ }^{105}$ Véase $\mathrm{A} / \mathrm{HRC} / 17 / 31$, anexo. 
mediante legislaciones, políticas, regulaciones y decisiones judiciales. Además, los Estados tienen la obligación de garantizar el acceso a mecanismos de reparación eficaces a las personas cuyos derechos hayan sido vulnerado por empresas mediante actividades en su territorio.

\section{Conclusiones}

Existen dos factores que impulsan el incremento del endeudamiento privado: en primer lugar, la pujanza de la oferta crediticia en el sector financiero, cuyos instrumentos favorecedores son la liberalización del mercado y el aumento de la financierización, que también incluyen la mercantilización y la financierización de los componentes esenciales para hacer efectivos los derechos económicos, sociales y culturales. En segundo lugar, la reconfiguración de muchas de las necesidades humanas de reproducción social que se convierten en necesidades financieras insatisfechas. Si bien en el siglo pasado se instituyeron y expandieron redes de seguridad social, los déficits que persisten son campo abonado para que florezca la deuda privada. Paradójicamente, las medidas de protección social adoptadas por los Estados, mediante transferencias de efectivo, se han utilizado como una posible caución de empréstitos para garantizar los préstamos del acreedor o imponer intereses más bajos, en lugar de servir para su finalidad original ${ }^{106}$.

La elevada deuda de lxs particulares y de los hogares, que constituye una proporción significativa de la deuda privada en la mayoría de los países, se ha relacionado con la desigualdad, la inestabilidad macroeconómica, la deuda soberana insostenible y las crisis financieras. Los salarios bajos, la pobreza y la desigualdad, que se han agravado por la adopción de políticas como las de privatización, austeridad y flexibilización del mercado laboral, han empujado a millones de personas a endeudarse,

${ }^{106}$ Véase Lena Lavinas de Morais, The Takeover of Social Policy by Financialization: The Brazilian Paradox (Palgrave MacMillan, Nueva York, 2017). 
lo que, a su vez, ha llevado a una gran proporción de ellas a la pobreza y al trabajo informal y, así, las ha hecho vulnerables a toda clase de abusos. En la raíz de este fenómeno está la denominada "inclusión financiera", el estrepitoso fracaso del Estado en cuanto a garantizar los derechos económicos, sociales y culturales de todos. El incremento explosivo de la deuda privada es lo que ha mantenido la demanda agregada y el crecimiento económico en los últimos decenios, con frecuencia a expensas de los hogares endeudados. Millones de personas de todo el mundo transfieren una parte apreciable de su riqueza y su bienestar al sector financiero, cuyos vínculos con la economía real se siguen erosionando, poniendo en peligro la prosperidad así como la estabilidad y la seguridad financieras de todxs y refuerza la desigualdad.

Lxs particulares y los hogares no deberían contraer deuda privada como medio de compensar el incumplimiento de las obligaciones que tienen los Estados de proteger, promover y hacer efectivos los derechos humanos. Los gastos financieros y de otro tipo que deban efectuar lxs particulares y los hogares por concepto de amortización de deuda deberían ser de una cuantía que no amenazara ni pusiera en peligro el ejercicio de los derechos humanos. El endeudamiento y la amortización de una deuda o el impago de esta no deberían dar lugar a violaciones de los derechos humanos.

En este artículo se explicó que el incremento de la inclusión financiera no produce, de manera necesaria y automática, mejoras en la vida real, un mayor goce de los derechos humanos, un desarrollo más sostenible o menos desigualdad. Es evidente que un número de Estados (y de instituciones financieras internacionales) promueven y defienden una política de gastos financiados con deuda a expensas de la provisión de bienes y servicios públicos.

No es de extrañar que la microfinanciación, que es la fórmula estelar global propugnada por los partidarios de la inclusión financiera para aliviar la pobreza, haya sido promovida, de 
manera generalizada, por actores financieros mundiales muy poderosos, que, a su vez, no están muy interesados en entablar debates de carácter más estructural, tales como la fiscalidad progresiva, el fraude fiscal, la economía del cuidado u otros medios de fortalecer los ingresos y las regulaciones estatales a fin de mejorar los programas de prestaciones sociales y garantizar el acceso a una serie de servicios esenciales.

Este artículo analizó las repercusiones negativas que tienen, en los derechos humanos, el microcrédito, la deuda sanitaria, educativa y de vivienda, las prácticas abusivas y coactivas de cobro, la criminalización de los deudores, la deuda de los consumidores, la deuda migratoria y la servidumbre por deudas. Teniendo en cuenta las razones que inducen a las personas a endeudarse por los medios que se acaban de citar, cabe concluir que la deuda privada puede ser tanto causa como consecuencia de vulneraciones de los derechos humanos. Esto explica por qué y cómo el descontento social, la desigualdad y los niveles insoportables de deuda privada se encuentran relacionados intrínsecamente.

Es cierto que la deuda privada se encuentra codificada de manera selectiva en las normativas nacionales ${ }^{107}$; sin embargo, los contratos de deuda se sitúan en un universo jurídico y económico más general, en el que el derecho de los derechos humanos interactúa con (y limita) los derechos de los acreedores. Aunque en general no se considere que las leyes de protección financiera de lxs consumidorxs y las que regulan la bancarrota lidien con asuntos de derechos humanos, en realidad sí que juegan un rol importante en estos asuntos. Por consiguiente, las normativas de defensa de los consumidores y de quiebra se deberían considerar como medios de prevenir posibles abusos de los prestamistas, salvaguardar los derechos humanos de lxs prestatarixs y compensar el desequilibrio de poder inherente que existe entre las partes que suscriben un contrato

\footnotetext{
107 Véase Katharina Pistor, The Code of Capital: How the Law Creates Wealth and Inequality (Princeton University Press, Princeton, 2019).
} 
de préstamo. A tal fin, se debería prever, e incluso fomentar, la posibilidad de que lxs consumidorxs de productos financieros se organizaran y negociaran colectivamente para compensar el desequilibrio de poder que existe entre los prestamistas y los prestatarixs. 